(c) American Dairy Science Association, 2005.

\title{
Genetic Analysis of Clinical Mastitis, Milk Fever, Ketosis, and Retained Placenta in Three Lactations of Norwegian Red Cows
}

\author{
B. Heringstad, ${ }^{1,2}$ Y. M. Chang, ${ }^{3}$ D. Gianola, ${ }^{1,3}$ and G. Klemetsdal ${ }^{1}$ \\ ${ }^{1}$ Department of Animal and Aquacultural Sciences, Norwegian University of Life Sciences, N-1432 Ås, Norway \\ ${ }^{2}$ Geno Breeding and Al Association, N-1432 Ås, Norway \\ ${ }^{3}$ Department of Dairy Science, University of Wisconsin, Madison 53706
}

\begin{abstract}
The objectives were to infer heritability and genetic correlations between clinical mastitis (CM), milk fever (MF), ketosis (KET), and retained placenta (RP) within and between the first 3 lactations and to estimate genetic change over time for these traits. Records of 372,227 daughters of 2411 Norwegian Red (NRF) sires were analyzed with a 12 -variate (4 diseases $\times 3$ lactations) threshold model. Within each lactation, absence or presence of each of the 4 diseases was scored based on the cow's health recordings. Each disease was assumed to be a different trait in each of the 3 lactations. The model for liability had trait-specific effects of yearseason of calving and age of calving (first lactation) or month-year of calving and calving interval (second and third lactations), herd-5-yr, sire of the cow, and a residual. Posterior means of heritability of liability in first, second, and third lactations were 0.08, 0.07, and 0.07, respectively, for $\mathrm{CM} ; 0.09,0.11$, and 0.13 for $\mathrm{MF}$; 0.14, 0.16 , and 0.15 for KET, and 0.08 in all 3 lactations for RP. Posterior means of genetic correlations between liability to $\mathrm{CM}, \mathrm{MF}$, KET, and RP, within disease between lactations, ranged from 0.19 to 0.86 , and were highest between KET in different lactations. Correlations involving first lactation MF were low and had higher standard deviations. Genetic correlations between diseases were low or moderate (from -0.10 to 0.40), within as well as between lactations; the largest estimates were for MF and KET, and the lowest involved MF or KET and RP. Positive genetic correlations between diseases suggest that some general disease resistance factor with a genetic component exists. Trends of average sire posterior means by birth-year of daughters were used to assess genetic change, and the results indicated genetic improvement of resistance
\end{abstract}

Received March 8, 2005.

Accepted May 9, 2005.

Corresponding author: B. Heringstad; e-mail: bjorg.heringstad @umb.no. to $\mathrm{CM}$ and KET and no genetic change for $\mathrm{MF}$ and $\mathrm{RP}$ in the NRF population.

(Key words: dairy cattle, disease, genetic correlation, threshold model)

Abbreviation key: $\mathbf{C M}=$ clinical mastitis, $\mathbf{K E T}=$ ketosis, $\mathbf{M F}=$ milk fever, $\mathbf{N R F}=$ Norwegian Red, $\mathbf{R P}=$ retained placenta.

\section{INTRODUCTION}

Clinical mastitis (CM), ketosis (KET), milk fever $(\mathbf{M F})$, and retained placenta $(\mathbf{R P})$ are among the most frequent diseases affecting dairy cattle. In Norway, $45 \%$ of all veterinary treatments in dairy cows in 2002 were for $\mathrm{CM}, 9 \%$ for KET, $8 \%$ for $\mathrm{MF}$, and $5 \%$ for RP (TINE, 2003).

Most genetic studies on diseases other than mastitis have been based on relatively small datasets and have used methods that do not take into account that disease is often scored as a categorical trait (e.g., absent or present). Several studies have reported heritability estimates for one or more of the previously mentioned disease traits (Solbu, 1984; Lyons et al., 1991; Mántysaari et al., 1991; Simianer et al., 1991; Uribe et al., 1995; Pryce et al., 1997; Schnitzenlehner et al., 1998; van Dorp et al., 1998; Wassmuth et al., 2000; Zwald et al., 2004a, b), but there are very few estimates of genetic correlations between these diseases. Exceptions are Pryce et al. (1997) and Zwald et al. (2004b), who reported genetic correlations between $\mathrm{MF}$ and mastitis $(0.64 ; \mathrm{SE}=0.11)$ and between KET and mastitis $(0.17$; $\mathrm{SD}=0.21)$, respectively.

Frequencies of all 4 diseases are higher in later lactations. A question of importance is, therefore, whether or not the traits can be considered to be the same across lactations. Pösö and Mäntysaari (1996) and Nielsen et al. (1997) found genetic correlations ranging from 0.65 to 1 between mastitis in the first 3 lactations. Heringstad et al. (2004) estimated genetic correlations between liability to CM in different intervals of the first 3 lactations of Norwegian Red (NRF), and their estimates ranged between 0.24 and 0.73. Mäntysaari et al. (1991) reported a genetic correlation of 0.68 between KET in 
Table 1. Mean frequency of clinical mastitis (CM), milk fever (MF), ketosis (KET), and retained placenta (RP) by lactation.

\begin{tabular}{lrrr}
\hline & First & \multicolumn{1}{l}{$\begin{array}{l}\text { Second } \\
\text { lactation }\end{array}$} & $\begin{array}{l}\text { Third } \\
\text { lactation }\end{array}$ \\
\hline Cows, no. & 372,227 & 247,692 & 147,051 \\
Mean CM frequency, ${ }^{1} \%$ & 15.8 & 19.8 & 24.2 \\
Mean MF frequency, \% & 0.1 & 1.9 & 7.9 \\
Mean KET frequency, \% & 7.5 & 13.0 & 17.2 \\
Mean RP frequency, \% & 2.6 & 3.4 & 4.3 \\
\hline
\end{tabular}

${ }^{1}$ Percentage of cows with at least one case of $\mathrm{CM}$ in the period from $15 \mathrm{~d}$ prior to calving to $120 \mathrm{~d}$ after calving.

the first and second lactations, and Schnitzenlehner et al. (1998) found a genetic correlation of 0.79 between $\mathrm{RP}$ in the first and second lactations.

In Norway, all veterinary treatments have been recorded on an individual cow basis since 1978 (Heringstad et al., 2000). Thus, NRF represents one of few dairy populations where assessment of genetic change for several diseases is possible. The objectives were to infer heritability of and genetic correlations between $\mathrm{CM}, \mathrm{KET}, \mathrm{MF}$, and RP within and between the first 3 lactations and to estimate genetic change for these traits in the NRF population. A Bayesian multivariate threshold model was fitted to NRF field data for this purpose.

\section{MATERIALS AND METHODS}

\section{Data}

Data on all cows included in the study by Heringstad et al. (2004) were used. Records were extracted from a dataset with 1.6 million cows, such that only first-crop daughters (i.e., when the difference between the birth year of a daughter and the birth year of her sire was $<6 \mathrm{yr}$ ) of the $2411 \mathrm{NRF}$ sires that were progeny tested from 1978 through 1998 were included. The data were further restricted to include only cows that had their first calving in a herd-5-yr class with at least 10 first lactation cows in the dataset. The edited dataset had 372,227 first lactation cows, of which $247,692 \mathrm{had}$ a second lactation and 147,051 had a third lactation.

For each cow, all cases of veterinary-treated CM, MF, $\mathrm{KET}$, and RP in the first 3 lactations were included in the dataset. Within each of the 3 lactations, absence or presence of each of the 4 diseases was scored as "0" or " 1 ", respectively, based on whether or not the cow had at least one veterinary treatment recorded within the interval from $15 \mathrm{~d}$ before to $120 \mathrm{~d}$ after calving for $\mathrm{CM}$ and KET, from $15 \mathrm{~d}$ before to $30 \mathrm{~d}$ after calving for $\mathrm{MF}$, and within the first $5 \mathrm{~d}$ after calving for RP. For CM, the interval from $15 \mathrm{~d}$ before to $120 \mathrm{~d}$ after calving was chosen because this is the interval used in the national genetic evaluation of CM in Norway. Mean disease frequencies, by lactation, are given in Table 1. For all
4 diseases, frequency was higher in second and third lactations. The mean frequency of CM was $15.8,19.8$, and $24.2 \%$ in first, second, and third lactations, respectively. The frequency of MF was very low in first lactation cows $(0.1 \%)$ and increased to 1.9 and $7.9 \%$ for cows in second and third lactations, respectively. The mean frequency of KET ranged from $7.5 \%$ in first lactation to $17.2 \%$ in third lactation cows; similarly, RP had an incidence of $2.6 \%$, increasing to $4.3 \%$ in third lactation. In Norway, the incidence of KET has decreased gradually since the mid 1980s. For first lactation cows, the mean frequency of KET decreased from $10.6 \%$ in 1987 to $4.3 \%$ in 1998 . The frequency of $\mathrm{MF}$ and $\mathrm{RP}$ varies somewhat between years without following any obvious phenotypic trend. The frequency of CM increased from 1978 to 1995 and decreased thereafter, as shown by Heringstad et al. (2004).

The sire pedigree file had 2726 males, including the 2411 sires with daughter records in the dataset.

\section{Model}

A 12-variate threshold-liability model (Gianola and Foulley, 1983; Foulley et al., 1987) was used, assuming that the 4 diseases were different traits in each of the lactations. Similar models have been used previously for analyzing $\mathrm{CM}$ in different time intervals within and between lactations (Chang et al., 2002, 2004; Heringstad et al., 2004). The threshold model postulates an underlying continuous variable, liability $(\lambda)$, such that the observed binary variable takes value 1 if $\lambda$ is larger than a fixed threshold and 0 otherwise. With binary data, the threshold and the residual variance are not identifiable; therefore, these parameters were set to 0 and 1 , respectively.

In matrix notation, the model fitted can be written as

$$
\lambda=\mathbf{X} \beta+\mathbf{Z}_{\mathbf{h}} \mathbf{h}+\mathbf{Z}_{\mathrm{s}} \mathbf{s}+\mathbf{e}
$$

where $\lambda$ is a vector of unobserved liabilities for the 12 "traits" (disease $\times$ lactation combinations); $\boldsymbol{\beta}$ is a vector of systematic effects; $\mathbf{h}$ is a vector of herd-5-yr effects; $\mathbf{s}$ is a vector of sire-transmitting abilities; $\mathbf{e}$ is the vector of residual effects; and $\mathbf{X}, \mathbf{Z}_{\mathbf{h}}$, and $\mathbf{Z}_{\mathbf{s}}$ are the corresponding incidence matrices. The vector $\boldsymbol{\beta}$ included effects of age at calving and year $\times$ season of calving for first lactation traits and preceding calving interval and month $\times$ year of calving for second and third lactation traits. Age of calving had 15 levels, and year $\times$ season of calving had 80 levels (each year was divided into 4 seasons: January through March, April through June, July through September, and October through December). Calving interval in previous lactations were in 9 classes, whereas month $\times$ year of calving had 229 and 
217 classes in second and third lactations, respectively. Because the frequency of MF in first lactation was very low $(0.1 \%$, as shown in Table 1$)$, well-known "extreme category problems" of the threshold model were alleviated by forming year $\times$ season of calving, instead of month $\times$ year of calving classes for first lactation traits. The order of vectors $\mathbf{h}$ and $\mathbf{s}$ was 300,396 and 32,712, respectively. All residual variances were set equal to 1. Residuals were assumed to be correlated within lactation but independent between lactations and were assumed to follow the multivariate normal distribution: $\mathbf{e} \sim N\left(\mathbf{0}, \mathbf{R}_{\mathbf{0}} \otimes \mathbf{I}\right)$, where $\mathbf{R}_{\mathbf{0}}$ is the block diagonal $12 \times$ 12 residual (co)variance matrix. In $\mathbf{R}_{\mathbf{0}}$, each of the three $4 \times 4$ blocks is the between-disease correlation matrix pertaining to the lactation in question.

\section{Bayesian Analysis}

A Bayesian approach employing MCMC methods was used for sampling from marginal posterior distributions of the parameters (Sorensen et al., 1995; Sorensen and Gianola, 2002), as applied by Chang et al. (2002, 2004) and Heringstad et al. (2004).

Prior distributions. Independent proper uniform priors, U(-99, 99), were assigned to each of the elements of $\boldsymbol{\beta}$. Multivariate normal prior distributions were assigned to the herd-5-yr effects, $\mathbf{h} \sim N\left(\mathbf{0}, \mathbf{H}_{\mathbf{0}} \otimes \mathbf{I}\right)$, and to the sire-transmitting abilities, $\mathbf{s} \sim N\left(\mathbf{0}, \mathbf{G}_{\mathbf{0}} \otimes \mathbf{A}\right)$. Here, $\mathbf{H}_{\mathbf{0}}$ and $\mathbf{G}_{\mathbf{0}}$ are the two $12 \times 12$ full (co)variance matrices of herd-5-yr and sire effects on the 12 traits, respectively, and $\mathbf{A}$ is the matrix of additive relationships between sires, of order 2726. Inverse Wishart prior distributions were used for matrices $\mathbf{H}_{\mathbf{0}}$ and $\mathbf{G}_{\mathbf{0}}$ : $\mathbf{H}_{\mathbf{0}} \sim I W\left(\nu_{h}, \mathbf{V}_{h}\right)$ and $\mathbf{G}_{\mathbf{0}} \sim I W\left(\nu_{g}, \mathbf{V}_{g}\right)$, where $\nu_{\mathrm{h}}$ and $\nu_{\mathrm{g}}$ are the degrees of freedom parameters and $\mathbf{V}_{\mathrm{h}}$ and $\mathbf{V}_{\mathrm{g}}$ are scale matrices. Hyper-parameters were as in $\mathrm{He}$ ringstad et al. (2004). The non-zero covariance elements of $\mathbf{R}_{\mathbf{0}}$ were assigned uniform priors bounded between -1 and 1 .

Posterior distributions. After augmentation with the 3,067,880 unobserved liabilities, the fully conditional distributions of all parameters, except that of $\mathbf{R}_{\mathbf{0}}$, can be written in closed form as described in Sorensen and Gianola (2002). Chang et al. (2002) give details of the Gibbs sampling scheme applied to parameters with known conditional posterior distributions. Because all residual variances are equal to 1 , the fully conditional distribution of $\mathbf{R}_{\mathbf{0}}$ does not have a closed form, so a random walk Metropolis-Hastings algorithm was used to sample residual correlations, as described by Chang et al. (2002).

Convergence diagnostics. Convergence was assessed with the method of Raftery and Lewis (1992) and using the first 20,000 iterations of the Gibbs chain.

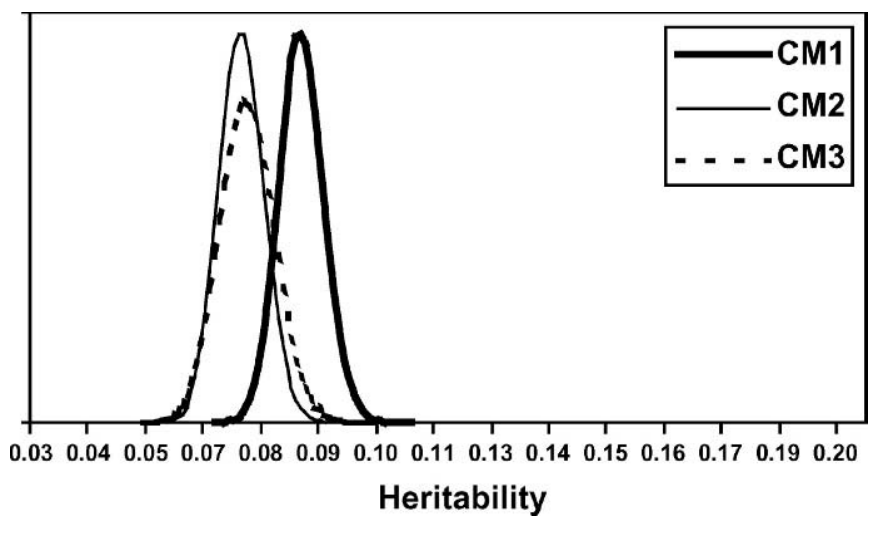

Figure 1. Posterior distributions of heritability $\left[h^{2}=4 \sigma^{2}{ }_{s} /\left(\sigma^{2}{ }_{s}+1\right)\right]$ of liability to clinical mastitis $(\mathrm{CM} i)$ in the first 3 lactations $(i=1$, $2,3)$.

Using the diagnostics plus visual inspections of trace plots, it was decided to run a single chain with a length of 400,000 iterations after a burn-in of 10,000 iterations. For parameters that do not involve first lactation MF, a total chain length of 100,000 would have been sufficient.

\section{Sire Evaluations and Genetic Change}

Genetic evaluations of sires (posterior means) were computed in the liability scale. These sire evaluations were transformed to the probability scale using the Gaussian link function $p_{i, j}=\Phi\left(\mu_{\mathrm{i}}+\bar{s}_{i, j}\right)$, where $p_{i, j}$ is the probability of trait $i(i=1,2, \ldots . ., 12)$ for daughters of sire $j, \Phi($.) is the standard normal distribution function, $\mu_{i}$ is the probit corresponding to the mean liability of trait $i$, and $\bar{s}_{i, j}$ is the posterior mean of liability to trait $i$ for sire $j$.

Genetic change was evaluated by plotting average sire posterior means against birth year of daughters. All daughters of the 2411 sires ( 1.6 million cows) were used for assessment of genetic change. Sires were weighted according to their number of daughters, so this measure reflects sire usage as well as possible genetic change in the NRF population.

\section{RESULTS AND DISCUSSION}

Figure 1 shows the posterior distributions of heritability of liability to CM. The 3 distributions overlap, but the Bayesian analysis suggests a larger heritability of CM in the first lactation than in the second and third lactations. Posterior mean estimates of heritability of liability to CM, of 0.08 in first lactation and 0.07 for second and third lactations (Table 2), agree with estimates from cross-sectional threshold model analyses of first lactation mastitis treated as a single binary trait, 
Table 2. Posterior means (SD) of heritability (on the diagonal) and genetic correlations (above the diagonal) for liability to clinical mastitis $(\mathrm{CM} i)$, milk fever $(\mathrm{MF} i)$, ketosis $(\mathrm{KET} i)$, and retained placenta $(\mathrm{RP} i)$ in the first 3 lactations $(i=1,2,3)$.

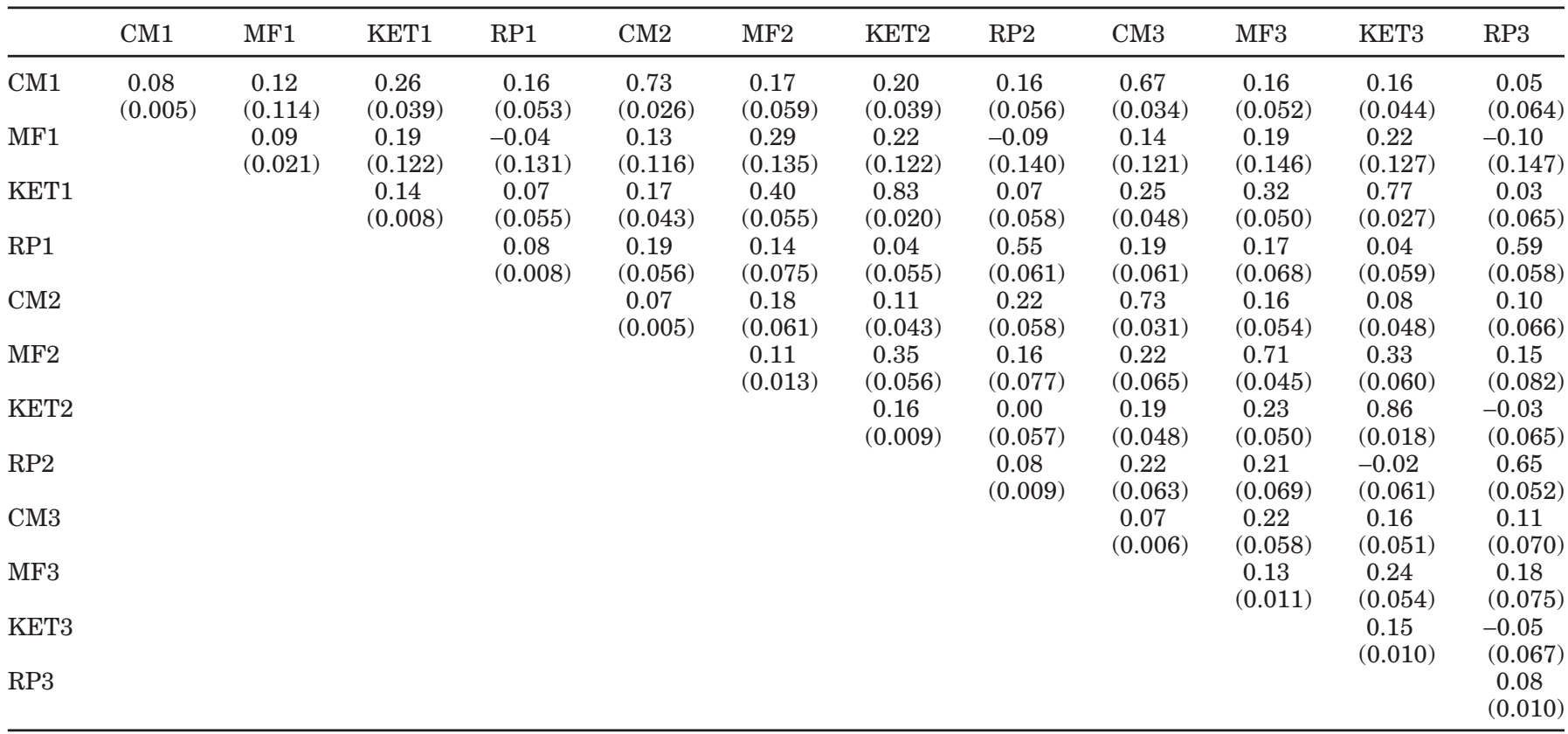

which range from 0.06 to 0.12 (Lund et al., 1999; Kadarmideen et al., 2001; Heringstad et al., 2003; Zwald et al., 2004a). A slightly higher heritability in first lactation than in second and third lactations agrees with results from a multivariate threshold model analysis of CM in 12 intervals of the first 3 lactations in NRF (Heringstad et al., 2004).

Posterior distributions of heritability of liability to MF in second and third lactations were sharp and symmetric (Figure 2), with posterior means (SD) of 0.11 $(0.01)$ and $0.13(0.01)$, respectively (Table 2$)$. Heritability of liability to MF in first lactation had a less peaked and slightly skewed posterior distribution (Figure 2),

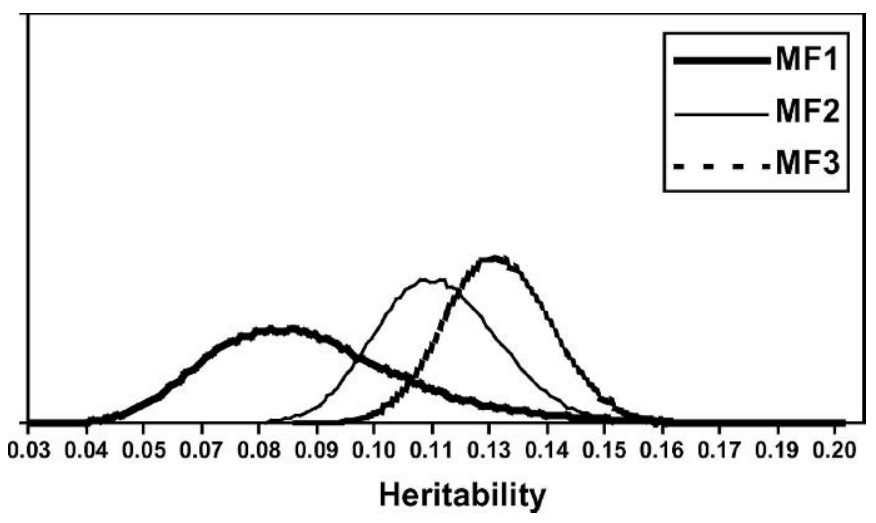

Figure 2. Posterior distributions of heritability $\left[\mathrm{h}^{2}=4 \sigma^{2}{ }_{\mathrm{s}} /\left(\sigma_{\mathrm{s}}^{2}+1\right)\right]$ of liability to milk fever (MFi) in the first 3 lactations $(i=1,2,3)$. with a posterior mean (SD) of $0.09(0.02)$ (Table 2). A low incidence of $\mathrm{MF}$ in first lactation cows (and, thus, little observed variability) implies imprecise corresponding parameters. Previously reported heritability estimates of MF across lactations vary between 0.08 and 0.47 (Lyons et al., 1991; Uribe et al., 1995; Pryce et al., 1997). For first lactation MF, van Dorp et al. (1998) found a heritability of 0.04 .

Figure 3 shows that the posterior distributions of heritability of liability to KET were sharp and symmetric in all 3 lactations and had considerable overlap. The posterior mean was $0.14,0.16$, and 0.15 for first, second, and third lactations, respectively (Table 2). All posterior

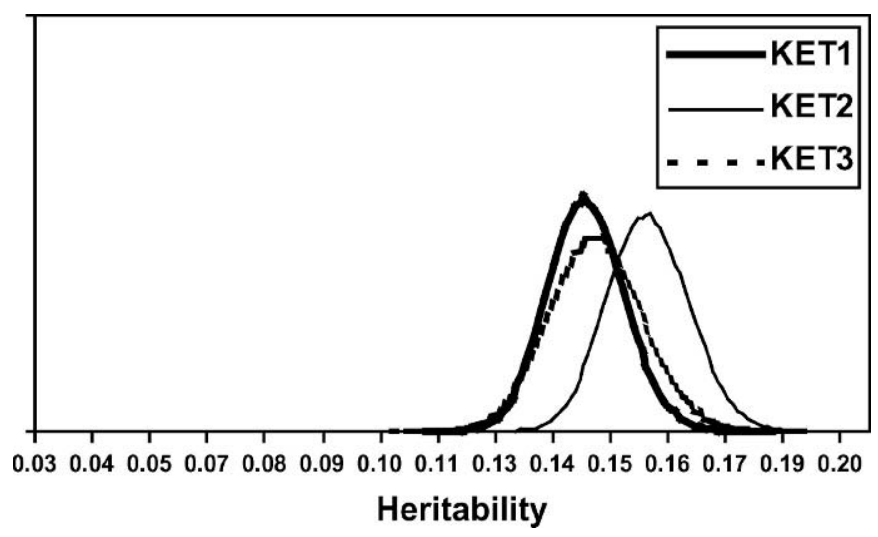

Figure 3. Posterior distributions of heritability $\left[\mathrm{h}^{2}=4 \sigma^{2}{ }_{\mathrm{s}} /\left(\sigma^{2}{ }_{\mathrm{s}}+1\right)\right]$ of liability to ketosis (KETi) in the first 3 lactations $(i=1,2,3)$. 


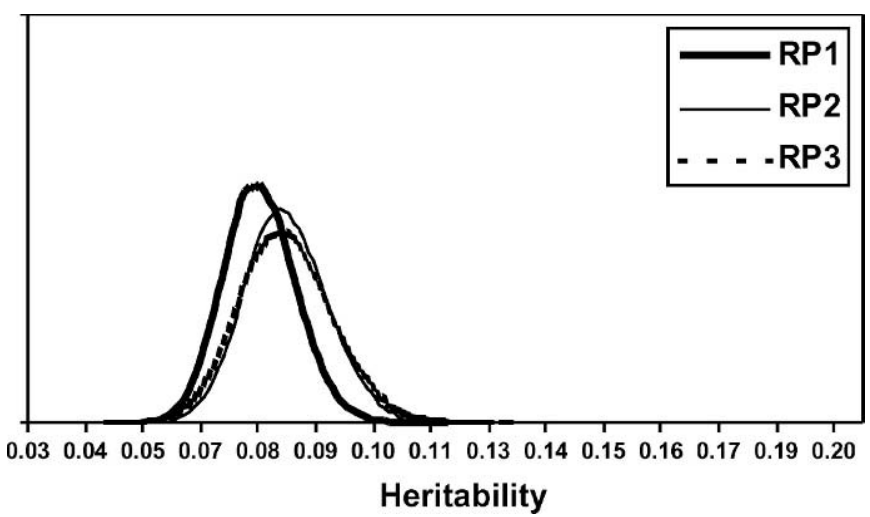

Figure 4. Posterior distributions of heritability $\left[\mathrm{h}^{2}=4 \sigma_{\mathrm{s}}^{2} /\left(\sigma^{2}{ }_{\mathrm{s}}+1\right)\right]$ of liability to retained placenta $(\mathrm{RP} i)$ in the first 3 lactations $(i=1$, $2,3)$.

standard deviations were $\leq 0.01$. Most estimates of heritability of KET from linear models range between 0.01 and 0.10 (Solbu, 1984; Lyons et al., 1991; Mäntysaari et al., 1991; Wassmuth et al., 2000); van Dorp et al. (1998) reported a heritability of KET of 0.39 . Because heritability estimates from linear models are dependent on disease incidence, these results cannot be compared directly. Estimated heritability of liability to KET from threshold models, or heritability estimates transformed to the underlying liability scale, range between 0.06 and 0.11 (Mäntysaari et al., 1991; Simianer et al., 1991; Uribe et al., 1995; Zwald et al., 2004a). Our heritability estimates for KET are higher than most literature values, with the posterior distributions (Figure 3) suggesting 0.11 as a lower bound for this parameter.

The posterior distributions of heritability of liability to RP in the 3 lactations had substantial overlap (Figure 4), with mean 0.08 and SD $\leq 0.01$ for any of the 3 lactations considered (Table 2). Schnitzenlehner et al. (1998) reported heritability estimates of $\mathrm{RP}$, transformed to the underlying scale, of 0.14 and 0.07 for first and second lactations, respectively. Other estimates of heritability of RP range from 0.004 to 0.08 (Lyons et al., 1991; van Dorp et al., 1998; Wassmuth et al., 2000). Our Bayesian analysis suggests a lower bound of 0.06 for heritability of liability to RP.

Posterior means of genetic correlations between liability to $\mathrm{CM}, \mathrm{MF}$, KET, and RP, within and between lactations, ranged from -0.10 to 0.86 (Table 2). In general, the largest genetic correlations were found for the same disease in different lactations. All genetic correlations involving RP were low, and none of the genetic correlations between RP and KET could be considered to be different from 0 . All genetic correlations involving first lactation MF had relatively large posterior SD (0.116 to 0.147$)$, reflecting the lack of variability and,

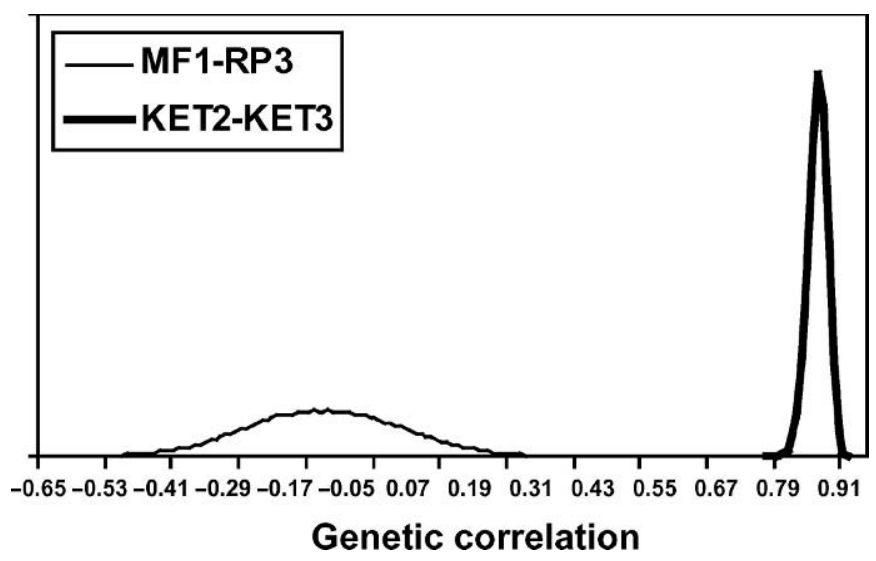

Figure 5. Posterior distributions of genetic correlations $\left(\mathrm{r}_{\mathrm{gi}, j}\right)$ between liability to disease $i$ and $j$. The posterior distributions with the highest mean and lowest standard deviation $\left(\mathrm{r}_{\text {gKET2,KET3 } 3}\right)$ and the lowest mean and the highest standard deviation $\left(\mathrm{r}_{\mathrm{gMF} 1, \mathrm{RP} 3}\right)$ are shown. MF1 = milk fever in first lactation, RP3 = retained placenta in third lactation, and $\mathrm{KET}=$ ketosis in second (2) and third (3) lactation.

thus, of covariability for this trait. Other genetic correlations had posterior SD between 0.018 and 0.082 . Figure 5 shows posterior distributions of the genetic correlation with the highest mean (KET2 and KET3) and the lowest mean (MF1 and RP3), which also were the distributions with the lowest and highest standard deviation.

Posterior distributions of genetic correlations between lactations, within disease, are given in Figure 6. The strongest genetic correlations were between second and third lactations, except for CM, where an equally strong correlation was found between first and second lactations. The genetic correlations between first and third lactations were less strong than other correlations for CM, MF, and KET.

The posterior mean (SD) of the genetic correlations between $\mathrm{CM}$ in different lactations were $0.73(0.026)$ between first and second lactations, $0.67(0.034)$ between first and third lactations, and 0.73 (0.031) between second and third lactations (Table 2). Our estimates are in agreement with those of Pösö and Mäntysaari (1996), but are lower than in Nielsen et al. (1997). Pösö and Mäntysaari (1996) found genetic correlations ranging from 0.67 to 0.90 between mastitis in the first 3 lactations. Nielsen et al. (1997) reported estimates of $0.96,0.95$, and 0.76 between first and second lactations for Red Danish, Danish Friesian, and Danish Jersey, respectively; between first and third lactations, estimates were $0.92,0.86$, and 0.65 , and between second and third lactations, the correlations were 1.0, 0.98, and 0.99. Heringstad et al. (2004) estimated genetic correlations between liability to CM in 12 intervals of 

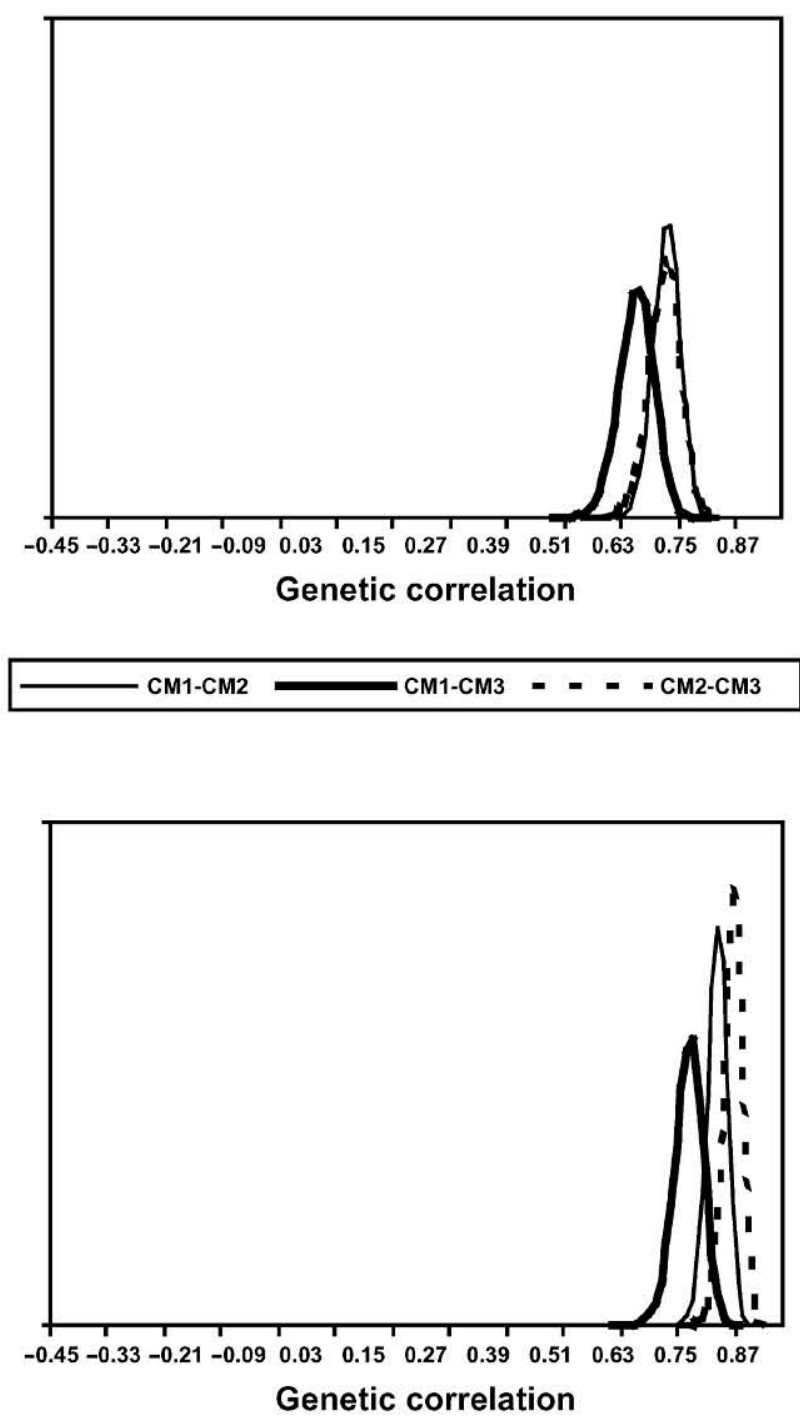

KET1-KET2 KET1-KET3 = - - - KET2-KET3
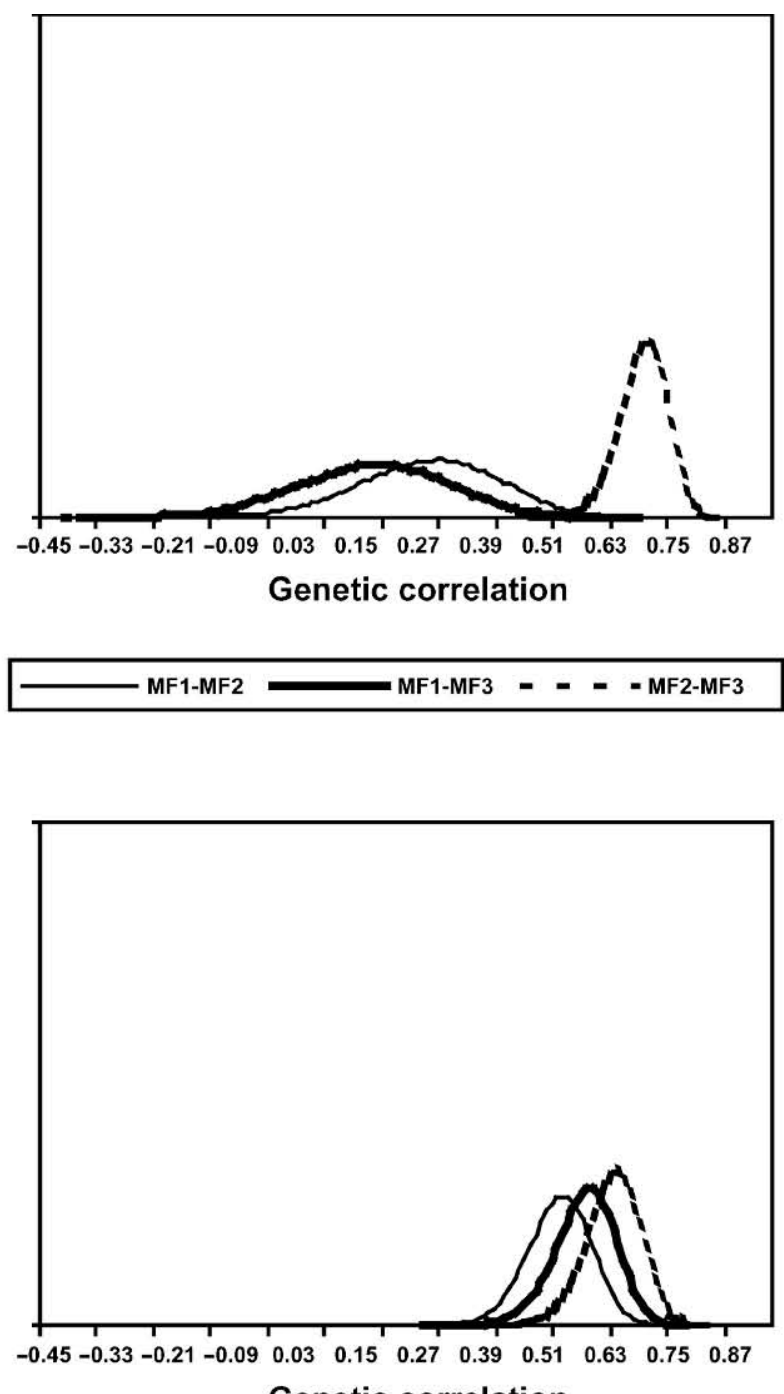

Genetic correlation

RP1-RP2 2 RP1-RP3 - - - - RP2-RP3

Figure 6. Posterior distributions of the genetic correlations between liability to clinical mastitis (CMi), milk fever (MFi), ketosis (KET $i$ ), and retained placenta $(\mathrm{RP} i)$ in lactation $i=1,2,3$.

the first 3 lactations, and estimates ranged from 0.24 to 0.73 .

Posterior means of the genetic correlations between MF in first and second lactations and first and third lactations were 0.29 and 0.19 , respectively (Table 2), with large standard deviations ( 0.135 and 0.146 , respectively). The genetic correlation between $\mathrm{MF}$ in second and third lactations had a sharper posterior distribution (Figure 6), with a mean (SD) of $0.71(0.045)$.

The posterior means (SD) of genetic correlations between KET in first and second, first and third, and second and third lactations were $0.83(0.020), 0.77$ (0.027), and $0.86(0.018)$, respectively (Table 2$)$. Mänty- saari et al. (1991) found a somewhat lower genetic correlation between KET in first and second lactation of Finnish Ayrshire cows (0.68).

The posterior means of genetic correlations between $\mathrm{RP}$ in first and second, first and third, and second and third lactations were $0.55,0.59$, and 0.65 , respectively, with SD between 0.052 and 0.061 (Table 2). These point estimates were lower than the 0.79 between RP in first and second lactations in Schnitzenlehner et al. (1998).

Genetic correlations much lower than one indicate that the diseases cannot be regarded as the same trait in different lactations. The results presented here suggest that KET (having the largest genetic correlations 
Table 3. Posterior means of herd-5-yr variance (on the diagonal), herd-5-yr correlations (above the diagonal), and residual correlations (below the diagonal) for liability to clinical mastitis (CMi), milk fever (MFi), ketosis $(\mathrm{KET} i)$, and retained placenta $(\mathrm{RP} i)$ in the first 3 lactations $(i=1,2,3)$.

\begin{tabular}{lllrrrrrrrrrr}
\hline & CM1 & MF1 & KET1 & RP1 & CM2 & MF2 & KET2 & RP2 & CM3 & MF3 & KET3 & RP3 \\
\hline CM1 & 0.14 & 0.16 & 0.37 & 0.32 & 0.86 & 0.20 & 0.36 & 0.28 & 0.78 & 0.27 & 0.36 & 0.22 \\
MF1 & 0.13 & 0.14 & 0.26 & 0.05 & 0.14 & 0.35 & 0.27 & 0.03 & 0.12 & 0.36 & 0.27 & 0.03 \\
KET1 & 0.01 & 0.10 & 0.39 & 0.19 & 0.30 & 0.06 & 0.89 & 0.16 & 0.27 & 0.14 & 0.85 & 0.15 \\
RP1 & 0.10 & 0.12 & -0.03 & 0.05 & 0.31 & 0.20 & 0.17 & 0.66 & 0.26 & 0.28 & 0.18 & 0.56 \\
CM2 & & & & & 0.13 & 0.26 & 0.33 & 0.25 & 0.90 & 0.33 & 0.34 & 0.23 \\
MF2 & & & & & 0.12 & 0.14 & 0.17 & 0.22 & 0.24 & 0.83 & 0.19 & 0.33 \\
KET2 & & & & & -0.02 & 0.13 & 0.32 & 0.14 & 0.33 & 0.22 & 0.96 & 0.19 \\
RP2 & & & & & 0.05 & 0.11 & -0.04 & 0.06 & 0.21 & 0.28 & 0.15 & 0.66 \\
CM3 & & & & & & & & 0.13 & 0.30 & 0.34 & 0.23 \\
MF3 & & & & & & & & -0.09 & 0.15 & 0.23 & 0.37 \\
KET3 & & & & & & & & 0.06 & 0.10 & -0.32 & 0.20 \\
RP3 & & & & & & & & & 0.04 & 0.07 \\
\hline
\end{tabular}

between lactations) can be considered for practical purposes to be the same trait in all 3 lactations, whereas MF seems to be a different trait in first and later lactations.

Genetic correlations between different diseases were low or moderate both within and between lactations; the highest values were between $\mathrm{MF}$ and KET, and the lowest estimates were between MF or KET and RP. The posterior means of the genetic correlations were between 0.12 and 0.22 for $\mathrm{CM}$ and $\mathrm{MF}$, between 0.08 and 0.26 for $\mathrm{CM}$ and KET, between 0.05 and 0.22 for $\mathrm{CM}$ and RP, between 0.19 and 0.40 for MF and KET, between -0.10 and 0.21 for MF and RP, and between -0.05 and 0.07 for KET and RP (Table 2).

Few estimates of genetic correlations between these 4 diseases have been published. Exceptions are Pryce et al. (1997), who estimated a genetic correlation between mastitis and $\mathrm{MF}$ of $0.64(\mathrm{SE}=0.11$ ) and Zwald et al. (2004b), who found a genetic correlation of 0.17 (posterior $\mathrm{SD}=0.21$ ) between mastitis and KET in first lactation Holsteins. As shown in Table 2, we found lower genetic correlations between $\mathrm{CM}$ and $\mathrm{MF}$ than did Pryce et al. (1997). Further, our point estimate of the genetic correlation between CM and KET in first lactation (0.26) was somewhat higher than that of Zwald et al. (2004b) and with a much smaller SD (0.039).

Some studies have reported genetic correlations between disease categories (Lyons et al., 1991; Nielsen et al., 1997). Lyons et al. (1991) estimated genetic correlations between health categories mammary and diges- tive (0.52), reproductive and digestive (0.38), and mammary and reproductive $(-0.11)$. Nielsen et al. (1997) analyzed 4 categories of diseases (udder, reproductive, digestive, and feet and leg diseases) in 3 lactations for 3 dairy breeds. For Danish Friesian, the genetic correlations between udder diseases and digestive, feet and leg, and reproductive diseases ranged from 0.21 to 0.29 , 0.26 to 0.28 , and 0.01 to 0.32 , respectively.

The low or moderate genetic correlations found between diseases are not surprising, as CM, MF, KET, and RP are very different diseases. Clinical mastitis is an infection of the udder, MF and KET are metabolic diseases, and RP is a fertility disorder. However, the fact that all genetic correlations between diseases that could be considered to be different from 0 were positive indicates the existence of some general disease resistance factor with a genetic component, which is consistent with knowledge about the major histocompatibility complex (Lewin et al., 1999).

The between herd-5-yr variance ranged from 0.05 to 0.39 (Table 3). Correlations between herd-5-yr effects were positive. Posterior means varied between 0.03 and 0.37 between different diseases and between 0.35 and 0.96 between the same disease in different lactations (Table 3); posterior SD were between 0.004 and 0.111 . All residual correlations were small, with posterior means between -0.04 and 0.13 (Table 3).

Rank correlations between sire posterior means within disease were from 0.90 to 0.97 for KET in different lactations, from 0.81 to 0.91 for $\mathrm{CM}$ and RP, and

Table 4. Rank correlations between sire posterior means for clinical mastitis (CM), milk fever (MF), ketosis $(\mathrm{KET})$, and retained placenta (RP) in first, second, and third lactations.

\begin{tabular}{lllll}
\hline & CM & MF & KET & RP \\
\hline First and second lactations & 0.88 & 0.72 & 0.93 & 0.81 \\
First and third lactations & 0.83 & 0.57 & 0.90 & 0.83 \\
Second and third lactations & 0.91 & 0.89 & 0.97 & 0.88 \\
\hline
\end{tabular}


Table 5. The top 10 sires based on clinical mastitis in first lactation (CM1) and their rank for liability to clinical mastitis $(\mathrm{CM} i)$, milk fever $(\mathrm{MF} i)$, ketosis $(\mathrm{KET} i)$, and retained placenta $(\mathrm{RP} i)$ in the first 3 lactations $(i=1,2,3)$.

\begin{tabular}{lrrrrrrrrrrr}
\hline CM1 & MF1 & KET1 & RP1 & CM2 & MF2 & KET2 & RP2 & CM3 & MF3 & KET3 & RP3 \\
\hline 1 & 245 & 24 & 81 & 4 & 73 & 121 & 233 & 4 & 160 & 208 & 248 \\
2 & 969 & 1069 & 915 & 2 & 323 & 1558 & 645 & 7 & 74 & 1472 & 1477 \\
3 & 51 & 32 & 135 & 85 & 72 & 48 & 360 & 76 & 44 & 54 & 443 \\
4 & 955 & 149 & 53 & 32 & 284 & 127 & 228 & 59 & 152 & 137 & 445 \\
5 & 9 & 14 & 72 & 200 & 33 & 14 & 719 & 348 & 1 & 7 & 569 \\
6 & 1743 & 270 & 882 & 34 & 2075 & 85 & 1223 & 14 & 2463 & 99 & 1634 \\
7 & 28 & 171 & 1790 & 1 & 299 & 65 & 1770 & 2 & 551 & 222 & 2342 \\
8 & 213 & 310 & 384 & 22 & 433 & 495 & 409 & 94 & 129 & 351 & 556 \\
9 & 606 & 441 & 733 & 19 & 403 & 362 & 1031 & 3 & 619 & 403 & 1486 \\
10 & 64 & 181 & 565 & 5 & 125 & 131 & 238 & 1 & 215 & 217 & 712 \\
\hline
\end{tabular}

between 0.57 and 0.89 for MF (Table 4). Rank correlations between sire posterior means between diseases ranged from -0.04 to 0.49 . Table 5 shows how the top 10 sires based on first lactation CM ranked for the other 11 traits. Some sires had a reasonably high ranking for most traits (e.g., sire 5 had a relatively high rank for all traits, except RP and second and third lactation CM). Other sires (e.g., 1, 2, and 7) had a high rank for CM but a low ranking for all other traits. This is not surprising, given the low rank correlations calculated.

Health traits have been included in the total merit index used for selection of NRF sires in Norway since 1978. The relative weight on CM in this index has gradually increased from $<3 \%$ in 1978 to $21 \%$ in 2004 . Ketosis was included in the total merit index from 1978 to 1996. The relative weight on KET was $<4 \%$ from 1978 to 1981 and was between 7 and 8.8\% from 1982 to 1993 . In 1994, the relative weight put on KET was reduced

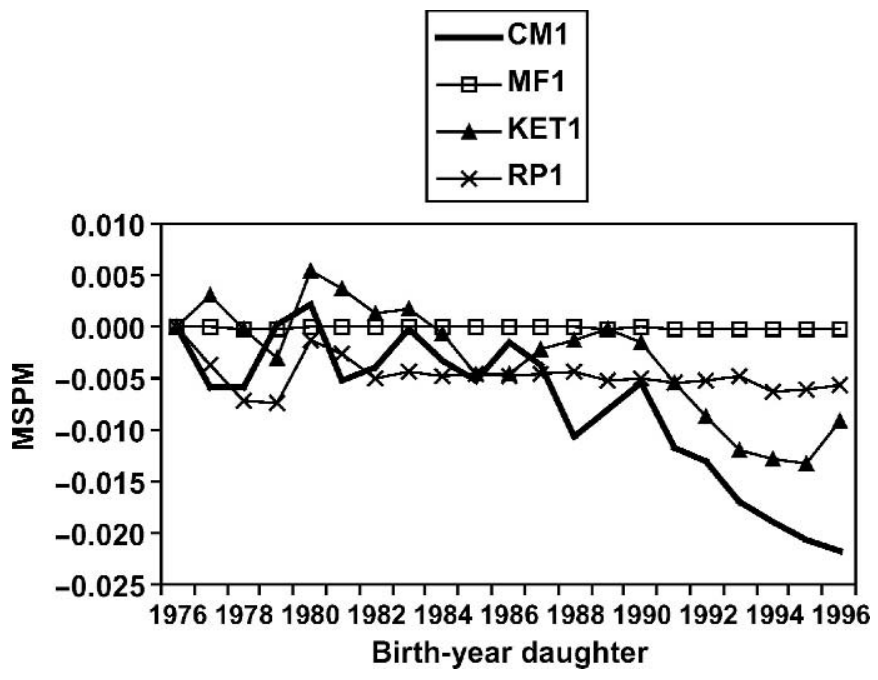

Figure 7. Average of sire posterior means (MSPM), in the probability scale, given as a deviation from MSPM for cows born in 1976, by birth year of daughters for first lactation clinical mastitis (CM), milk fever (MF), ketosis (KET), and retained placenta (RP). to $1.8 \%$. Ketosis was replaced by "other diseases," a trait that includes MF, KET, and RP, in 1997 and receives a relative weight of 3\% in the current total merit index.

Averages of sire posterior means (transformed to the probability scale) for CM, MF, KET, and RP in first lactation by birth year of daughters are given in Figure 7. All trends are presented as deviations from the average of the sire posterior means of sires of cows born in 1976. For MF and RP, the plots were flat, indicating no genetic change. The plot for KET was less smooth, but shows an overall decreasing trend from 1980 to 1995. For CM, the trend was relatively flat in the beginning, suggesting little or no genetic change, and decreasing toward the end of the time period. This trajectory is in agreement with Heringstad et al. $(2003,2004)$, who reported genetic improvement of mastitis resistance for NRF in recent years. Trends for second and third lactations were similar, but with more variation between years.

\section{CONCLUSIONS}

Point estimates of heritability of liability were 0.07 to 0.08 for CM, 0.09 to 0.13 for MF, 0.14 to 0.16 for $\mathrm{KET}$, and 0.08 in all 3 lactations for RP.

Genetic correlations within disease between lactations ranged from 0.19 to 0.86 and were highest between KET and lowest between MF in different lactations.

Genetic correlations between diseases were low or moderate ( -0.10 to 0.40$)$, highest between MF and KET, and lowest between MF or KET and RP. All genetic correlations that could be considered to be different from zero were positive.

Assessments of genetic change in the NRF population indicated genetic improvement for resistance to CM and KET and no genetic change for MF and RP.

\section{ACKNOWLEDGMENTS}

Access to the data was given by the Norwegian Dairy Herd Recording System and the Norwegian Cattle 
Health Service in agreement number 011.2000 by 12.10.2000. Geno Breeding and AI Association are acknowledged for providing pedigree information on sires. This work is part of the "Healthy Cow" project financed by the Research Council of Norway. Support was also received from the Babcock Institute for International Dairy Research and Development, University of Wisconsin, Madison and by grants NRICGP/USDA 200335205-12833 and NSF DEB-008.9742.

\section{REFERENCES}

Chang, Y. M., D. Gianola, B. Heringstad, and G. Klemetsdal. 2002. Correlations between clinical mastitis in different periods of first lactation Norwegian Cattle using a multivariate threshold model. Pages 177-192 in Case Studies in Bayesian Statistics. Vol 6. C. Gatsonis, A. Carriquiry, A. Gelman, D. Higdon, R. Kass, D. Pauler, and I. Verdinelli, ed. Springer Verlag, New York, NY.

Chang, Y. M., D. Gianola, B. Heringstad, and G. Klemetsdal. 2004. Effects of trait definition on genetic parameter estimates and sire evaluation for clinical mastitis with threshold models. Anim. Sci. 79:355-364.

Foulley, J. L., S. Im, D. Gianola, and I. Hoeschele. 1987. Empirical Bayes estimation of genetic value for $n$ binary traits. Genet. Sel. Evol. 19:197-224.

Gianola, D., and J. L. Foulley. 1983. Sire evaluation for ordered categorical data with a threshold model. Genet. Sel. Evol. 15:201-223.

Heringstad, B., Y. M. Chang, D. Gianola, and G. Klemetsdal. 2004. Multivariate threshold model analysis of clinical mastitis in multiparous Norwegian Dairy Cattle. J. Dairy Sci. 87:3038-3046.

Heringstad, B., G. Klemetsdal, and J. Ruane. 2000. Selection for mastitis resistance in dairy cattle-A review with focus on the situation in the Nordic countries. Livest. Prod. Sci. 64:95-106.

Heringstad, B., R. Rekaya, D. Gianola, G. Klemetsdal, and K. A. Weigel. 2003. Genetic change for clinical mastitis in Norwegian Cattle: A threshold model analysis. J. Dairy Sci. 86:369-375.

Kadarmideen, H. N., R. Rekaya, and D. Gianola. 2001. Genetic parameters for clinical mastitis in Holstein-Friesians in the United Kingdom: A Bayesian analysis. Anim. Sci. 73:229-240.

Lewin, H. A., M. Amills, and V. K. Ramiya. 1999. Molecular genetics of molecules with immunological functions: Major histocompatibility complex, immunoglobulins, T-cell receptors, cytokines and theirs receptors. Pages 163-197 in The Genetics of Cattle. R. Fries and A. Ruvinsky, ed. CABI Publishing, New York, NY.

Lund, M. S., J. Jensen, and P. H. Petersen. 1999. Estimation of genetic and phenotypic parameters for clinical mastitis, somatic cell production deviance, and protein yield in dairy cattle using Gibbs sampling. J. Dairy Sci. 82:1045-1051.
Lyons, D. T., A. E. Freeman, and A. L. Kuck. 1991. Genetics of health traits in Holstein cattle. J. Dairy Sci. 74:1092-1100.

Mäntysaari, E. A., Y. T. Gröhn, and R. L. Quaas. 1991. Clinical ketosis: Phenotypic and genetic correlations between occurrences and with milk yield. J. Dairy Sci. 74:3985-3993.

Nielsen, U. S., G. A. Pedersen, and J. Jensen. 1997. Genetic correlations among health traits in different lactations. Interbull Bull. 15:68-77.

Pösö, J., and E. A. Mäntysaari. 1996. Relationships between clinical mastitis, somatic cell score, and production in the first three lactations of Finnish Ayrshire. J. Dairy Sci. 79:1284-1291.

Pryce, J. E., R. F. Veerkamp, R. Thopson, W. G. Hill, and G. Simm. 1997. Genetic aspects of common health disorders and measures of fertility in Holstein Friesian dairy cattle. Anim. Sci. 65:353360.

Raftery, A. L., and S. Lewis. 1992. How many iterations in the Gibbs sampler? Pages 763-774 in Bayesian Statistics 4. J. M. Bernando, J. O. Berger, A. P. Dawid, and A. F. M. Smith, ed. Oxford University Press, Oxford, UK.

Schnitzenlehner, S., A. Essel, and J. Solkner. 1998. Retained placenta: Estimation of nongenetic effects, heritability and correlations to important traits in cattle. J. Anim. Breed. Genet. 115:467-478.

Simianer, H., H. Solbu, and L. R. Schaeffer, 1991. Estimated genetic correlations between disease and yield traits in dairy cattle. J. Dairy Sci. 74:4358-4365.

Solbu, H. 1984. Disease recording in Norwegian dairy cattle. II: Heritability estimates and progeny testing for mastitis, ketosis and "all diseases." Z. Tierzüchtg. Züchtgsbiol. 101:51-58.

Sorensen, D. A., S. Andersen, D. Gianola, and I. Korsgaard. 1995. Bayesian inference in threshold models using Gibbs sampling. Genet. Sel. Evol. 27:229-249.

Sorensen, D., and D. Gianola. 2002. Likelihood, Bayesian, and MCMC Methods in Quantitative Genetics. Springer-Verlag, New York.

TINE. 2003. TINE Produsentrådgiving Statistikksamling 2002. TINE, As, Norway. (In Norwegian with English tables.)

Uribe, H. A., B. W. Kennedy, S. W. Martin, and D. F. Kelton. 1995. Genetic parameters for common health disorders of Holstein cows. J. Dairy Sci. 78:421-430.

van Dorp, T. E., J. C. M. Dekkers, S. W. Martin, and J. P. T. M. Noordhuizen, 1998. Genetic parameters of health disorders, and relationships with 305-day milk yield and conformation traits of registered Holstein cows. J. Dairy Sci. 81:2264-2270.

Wassmuth, R., D. Boelling, P. Madsen, J. Jensen, and B. Beck Andersen. 2000. Genetic parameters of disease incidence, fertility and milk yield of first parity cows and the relation to feed intake of growing bulls. Acta Agric. Scand. Sect. A Anim. Sci. 50:93-102.

Zwald, N. R., K. A. Weigel, Y. M. Chang, R. D. Welper, and J. S. Clay. 2004a. Genetic selection for health traits using producerrecorded data. I. Incidence rates, heritability estimates, and sire breeding values. J. Dairy Sci. 87:4287-4294.

Zwald, N. R., K. A. Weigel, Y. M. Chang, R. D. Welper, and J. S. Clay. 2004b. Genetic selection for health traits using producerrecorded data. II. Genetic correlations, disease probabilities, and relationships with existing traits. J. Dairy Sci. 87:4295-4302. 